Canadian

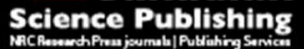

Canadian Journal of Civil Engineering Revue canadienne de génie civil

\title{
Risk Level Problems Affecting Microtunneling Projects Installation
}

\begin{tabular}{|r|l|}
\hline Journal: & Canadian Journal of Civil Engineering \\
\hline Manuscript ID & cjce-2017-0176.R1 \\
\hline Manuscript Type: & Article \\
\hline Date Submitted by the Author: & $13-J u l-2017$ \\
\hline Complete List of Authors: & $\begin{array}{l}\text { Salem, Dalia; Purdue University System, School of Construction } \\
\text { Management; } \\
\text { Elwakil, Emad; Purdue University, Building Construction Management } \\
\text { Hegab, Mohamed; California State University Northridge }\end{array}$ \\
\hline $\begin{array}{r}\text { Is the invited manuscript for } \\
\text { consideration in a Special } \\
\text { Issue? : }\end{array}$ & N/A \\
\hline Keyword: & Microtunneling, Risk level, Trenchless Technology, Clustering Analysis, AHP \\
\hline &
\end{tabular}

SCHOLARONE $^{\text {m }}$

Manuscripts 


\section{Affecting Microtunneling Projects Installation}

\section{Authors:}

4 Dalia Salem, Ph.D. student, School of Construction Management, Purdue University, West

5 Lafayette, IN, 47907, USA, (corresponding author) email: dsalem@purdue.edu

6 Emad Elwakil, Assistant Professor, School of Construction Management, Purdue University,

7 West Lafayette, IN, 47907, USA, email: eelwakil@purdue.edu

8 Mohamed Hegab, Professor, Civil Engineering and Construction Management Department,

9 California State University, Northridge, 91330, USA, email mhegab@csun.edu

10

11 Corresponding Author

12 Dalia Salem, MSc.

13 School of Construction Management

14 Purdue University

15 KNOY Hall

16401 N. Grant St.

17 West Lafayette, IN, 47907

18 Phone: 1(765)409-7332

19 Email dsalem@purdue.edu 


\section{Risk Level Problems Affecting Microtunneling Projects Installation}

\section{Abstract}

22 Microtunneling is a complex trenchless excavation process. Efficient microtunneling methods is

23 necessary to identify risk level problems that often require the integration of supporting

24 equipment and personnel. A clearer understanding of risk level problems will facilitate the

25 enhancement and modeling of risk assessments for future microtunneling projects. This study

26 investigates twelve different factors to assess risk level problems in microtunneling projects. The

27 factors and factors' weight are collected using a questionnaire sent to microtunneling-industry

28 specialists. A risk level prediction model is developed using the clustering analysis technique and

29 the Analytical Hierarchy Process (AHP) to consider the qualitative factors involved in the

30 microtunneling process. The model is then validated, which shows reasonable results with $89 \%$

31 Average Validity Percent. The main objective of the developed model is to assist contractors in

32 the bidding and operation phases of microtunneling projects by providing reasonably accurate 33 mitigation models.

35 Keywords: Microtunneling, Risk Level, Trenchless Technology, Clustering Analysis, AHP

\section{Introduction}

Trenchless Technology is a special tunneling technique that can be defined as

39 "Environmental sound technologies" (EST) which is used in the installation of new pipes. This

40 technique is in high demand due to the need for utility line replacement or repairs with minimum

41 disruption to the surface during installation (Hegab and Salem 2010). Trenchless Technology is

42 an environmentally friendly technique that helps in reducing pollutants to the environment, 
43 reserving natural resources, and handling waste. It is "a family of methods, materials, and

44 equipment capable of being used for the installation of new, replacement, or rehabilitation of 45 existing underground infrastructure with minimal disruption to surface traffic, business, and 46 activities" (Hashemi 2008). In addition, Trenchless Technology methods are used for repairing, 47 upgrading or installing underground infrastructure systems to offer less surface disruption 48 compared to open-cut methods (Mohanapriya and Kumar 2015).

The concept of microtunneling can be defined as "a trenchless construction method for

51 installing pipelines with all of the following features utilized: remote-controlled from a control

52 panel on ground surface, laser guided, pipe sections jacked simultaneously as spoil is excavated,

53 and continuous support at the face of the excavation" (ASCE 2001). The main advantage of

54 microtunneling is its capability to install pipes with a low risk of injury and less damage to 55 overall ground settlements, structures and roads in an urban environment (Luo 2007).

The differences between microtunneling and the pipe jacking method can be 58 demonstrated in the diameter of pipe installations. Microtunneling involves pipe installations up 59 to $900 \mathrm{~mm}$ in diameter; however, pipe jacking involves pipe installations greater than $900 \mathrm{~mm}$ in 60 diameter (PJA, 1995; (Khondoker et al. 2016). In 1890, the pipe jacking method first appeared in 61 the US, which has been defined as the minimal surface disruption pipe installation method

62 (Drennon 1970; Khondoker et al. 2016). In the 1950s, the UK used the pipe jacking method in 63 short-length installations in crowded urban areas, followed by Japan and Germany (Yonan 1993;

64 Khondoker et al. 2016). 
However, the definition of microtunneling slightly differs in Europe, Japan, and the

67 United States of America (USA). Europe and Japan define a pipe-jacking machine as a

68 microtunneling machine based on its size. In Japan, any size below 800 metric linear units may

69 be considered a microtunneling machine whereas in Europe the margin is 1000 metric linear

70 units (Thomson 1993). USA contractors define any remotely controlled, guided pipe-jacking

71 machine as a microtunneling machine (Salem and Hegab 2001). In addition, the microtunneling

72 technique is applied in various projects such as gravity and pressure lines, permanent ducts for

73 cables, and crossings beneath railways or roads. Monitoring and controlling the construction

74 productivity of pilot tube microtunneling (PTMT) are important in reducing the delays of

75 tunneling projects and in decreasing project costs (Tang 2015). Many factors affect risk level

76 problems of microtunneling projects installation. The literature review describes these factors are

77 site condition, geological condition, installing geometry, project contract, and trenchless method

78 (Islam et al. 2013).

79 In spite of an extensive variety of outstanding studies in microtunneling installation

80 projects. Risk level problems have not been applied more often to microtunneling projects

81 installation (Ali et al. 2007; Hegab and Salem 2010 ; Marzouk et al. 2010; Hegab and Smith

82 2007; Chung et al. 2004; Zayed and Mahmoud 2013)

83 This paper presents findings from a depth interviews with microtunneling experts on the 84 current risk level problems of microtunneling projects installation.

\section{Research Objectives}


The main objective of this research is to understand and quantify the risk levels of

88 microtunneling project problems to facilitate, enhance and model risk assessment. The objectives

89 can be broken down into the following sub-objectives:

90

91

92

93

94

95

96

97

99

100

101

102

103

104

105

106

107

108

109
- Analyze and identify the qualitative risk level factor of microtunneling projects.

- Determine the significant factors that highly contribute to the risk level prediction of microtunneling projects.

- Rank these factors using the Analytic Hierarchy Process modeling technique.

- Build an assessment model based on these factors.

- Validate the developed model.

\section{Background and Significance}

Various assessment modeling tools have been developed by researchers and professionals for underground construction utility projects using general construction risk evaluation methods. Ariaratnam (2007) studied the risks involved in the Horizontal Directional Drilling (HDD) and the Open Cut (OC) excavation. The study utilized the Total Risk Index Model (TRI) to calculate the risk value for underground urban utility projects based on the results of a questionnaire survey sent to users and specialists. The model helped calculate the risk value in less time, though it is based on questionnaire results that may vary in the future (Ariaratnam et al. 2007).

Ma et al. (2010) developed a model to quantify the risk of Maxi HDD projects utilizing Fuzzy Comprehensive Evaluation Method (FCEM) and Analytical Hierarchy Process (AHP). FCEM is utilized in complicated projects; however, it provides risk evaluation theoretically instead of mathematically (Ma et al. 2010). 
111 Gierczak (2014) focused on developing a model used for evaluating the safety risk of

112 Mini, Mid, Maxi HDD projects based on Fuzzy Fault Tree Analysis (FFTA). The model is

113 designed for any type of construction practice, but it consumes time due to its use of complex 114 calculations (Gierczak 2014).

115

116 Hyun (2015) developed a risk assessment methodology model for underground

117 construction projects based on a fuzzy concept coded for subway projects. The methodology

118 evaluates the factors affecting the risk of a probabilistic analysis module, but the software

119 focuses on subway projects only (Hyun et al. 2015).

120

121 Moganti (2016) developed a hierarchical safety risk assessment framework for 122 investigating the safety risks of HDD projects. The model focused on the factors and 123 characteristics of projects presented in two case studies. However, the model needs to be further

124 investigated and extensively evaluated using more real world case studies to be considered as an 125 efficient practice tool (Moganti 2016).

Most of the previous literature developed tools to enhance the decision support system of 128 underground construction. These studies, however, overlooked other factors affecting the risks of 129 microtunneling installation projects. Therefore, understanding the relative importance of each

130 factor is essential to model and predict risk level assessment models used in the installation of 131 microtunneling projects. In this study, a questionnaire was sent to microtunneling-industry 132 experts asking for their opinions about the risk levels that affect microtunneling installation as 
133 well as the importance and significance of these risk levels. The questionnaire analysis resulted 134 in twelve factors as shown in Table 1.

\section{Research Methodology}

This paper presents the analysis of the qualitative factors that resulted from the

140 questionnaire's responses and the literature. Clustering analysis technique and Analytical

141 Hierarchy Process (AHP) are used to assess the effect of the twelve factors and to incorporate

142 them into a risk level prediction model.

Figure 1 shows the flow chart of detailed work tasks involved in this study to achieve the

145 objectives of this research. The proposed framework consists of five main sections. It begins

146 with a comprehensive literature review followed by data collection. Data collection is conducted

147 by a pilot survey to determine the most remarkable factors, which affect the risk level problems

148 of microtunneling process installation. The survey is conducted based on the experts' opinion of

149 contractors, engineers and manufacturers in the microtunneling industry. To classify the data into

150 homogenous groups, clustering analysis techniques are utilized to identify a group of cases based

151 on the similarity of the variables in these groups. In the clustering analysis technique, the

152 hierarchical method is performed first to define the number of clusters, then the K-means cluster

153 analysis is used to form the clusters. An AHP model is utilized to assess risk level prediction 
154 problems. After developing the AHP model, a validation technique is conducted to check the 155 robustness and the capability of the developed model. The last section includes the conclusion 156 and future results.

\section{Data Collection}

A questionnaire was prepared and conducted by phone to assess the effect of the risk

162 level problem factors on the microtunneling projects' installation. The data were obtained from

163 twenty four experts with almost 20 years of experience in the area of microtunneling projects.

164 The experts were asked to mention and rank the effect a number of factors had on the prediction

165 of risk levels in microtunneling projects. The data results were based on 12 factors. The 166 questionnaire asked the respondents to rate the importance of variables using a 1-5 scale. 167 Because Saaty (1980) recommended a fuzzy scale of 1-10, the rating of each factor was 168 converted from a 1-5 scale to a 1-10 scale using proportional percentages as shown in Table 2.

\section{Background of Cluster Analysis}


176 into a number of different subgroups/clusters based on similarity (Jain et al. 1999). The aim of

177 cluster analysis is to classify the data set based on the assumption that the sets belonging to the

178 same clusters are as similar as possible (Elwakil 2011). In addition, cluster analysis is used to 179 identify groups of cases if the grouping is not previously known. Cluster analysis can be carried 180 out using a number of different methods. The methods can be classified as follows:

181

- Hierarchical method, which is the most common method, consists of two sub methods as shown below.

- Agglomerative methods: start from n clusters, to get to one cluster.

- Divisive methods: start from one cluster, to get to n cluster.

- Non-hierarchical ways referred to as the K-means clustering method is a methodology used to quickly cluster large knowledge sets, which usually takes a short amount of time to reason with the most popular class-conscious cluster analysis.

- Two-step cluster analysis takes a while to compute with the preferred hierarchical cluster analysis.

\section{Background of Analytic Hierarchy Process}

Analytic Hierarchy Process is a mathematical process that inputs the subjective and

195 personal preferences of individuals to produce a decision (Saaty 1999). Furthermore, the

196 hierarchical structure of system functions and the relative impacts of its elements are the two

197 main components of AHP (Saaty 1980). The AHP hierarchies are based on the human process of 
198 clustering any problem such that the interaction of the components of the clusters' impact on the

199 final decision can be studied (Saito and Sinha 1989).

Clustering can be performed through several steps. First, a deeper understanding of the

202 components of a hierarchical structure and their independence should be considered. Then,

203 mathematical matrix theory should be used to evaluate the relative contributions of the elements

204 in that level toward the element of the upper level (Saaty 1980). The AHP uses eigen values to

205 evaluate this relative contribution by a means of pair wise comparisons. Performing the pair wise

206 comparison requires a scale to represent the qualitative preference of the decision-makers. This

207 scale also reflects the relative weights among the different variables. Saaty (1980) suggested a

208 qualitative scale ranging from 1-9 because it corresponds with the human ability to measure 209 subjective factors.

210

211 Clustering Data Analysis

The main goal of using cluster analysis is to classify the data sets into groups that are

213 relatively homogeneous in characteristics on the basis of a defined set of variables. These groups

214 are called clusters. SPSS definition is "a sophisticated piece of software used by social scientists

215 and other professionals for statistical analysis" (Coakes and Steed 2009). SPSS offers three

216 methods for cluster analysis: Hierarchical Cluster, K-Means Cluster, and Two-Step Cluster. In

217 our research, using SPSS clustering techniques is efficient in quickly grouping our data sets into

218 clusters. This approach first performs the hierarchical method to define the number of clusters

219 then uses the K-means cluster analysis to form the clusters. The method is broken down into

220 smaller steps as follows: 


\section{1- Hierarchical Cluster Analysis}

222

223

224

225

226

227

228

229

230

231

232

233

234

235

236

237 Determine the number of clusters. Apply the elbow rule: identify the step where the "distance

238 coefficients" make a bigger jump. After performing the equation, we found that the data can be

239 classified into four clusters.

Where $\mathrm{d}$ : distance between cases $\mathrm{i}$ and $\mathrm{j}$.

- Link the clusters. Apply Ward's methods to the principal components score. Compute sum of squared distances within clusters. Aggregate clusters with the minimum increase in the overall sum of squares.

- Choose a solution by selecting the right number of clusters. Check the agglomeration schedule as shown in Table 3.

Table 3: Agglomeration schedule shows the step of elbow stage

Page 11 of 36

https://mc06.manuscriptcentral.com/cjce-pubs 

The number of clusters $=$ the number of cases- the step of elbow stage

$$
=24 \quad-\quad 20 \quad=\quad 4 \text { clusters }
$$

\section{2- K-Means Cluster Analysis}

257 the risk level factors. The model passes through several steps to apply the AHP technology as 258 shown below.

- $\quad$ Repeat the analysis using the K-Means technique.

- $\quad$ Set 4 as the number of clusters.

- $\quad$ Save cluster membership for each case as shown in Table 4.

We convert the four clusters into a fuzzy scale that ranges from Very low to High risk assessment level as shown in Table 5.

Table 4: Final output shows cluster membership

Table 5: Classifying the clusters into six clusters based on a fuzzy scale

\section{AHP Application to Risk Level Prediction Model}

To rate the qualitative factors in microtunneling projects, the AHP is developed based on

Page 12 of 36

https://mc06.manuscriptcentral.com/cjce-pubs 


\section{1- Setting up the hierarchy}

The AHP technique is used in calculating the $\mathrm{W}_{\mathrm{i}}$ for every qualitative variable (Dias and

263 Ioannou 1995; Saito and Sinha 1989). Defining the problem and developing the hierarchy is the

264 first step in the AHP model. The problem is represented accurately by breaking it down into its

265 components. The goal, criteria/factors, and the alternatives are the three main levels of the

266 hierarchy. The first level is the main goal of the decision-maker. The second level shows various

267 criteria/factors that remarkably contribute to the main goal in the first level. The last and third

268 level of the hierarchy is the alternatives. The AHP model evaluates these alternatives in respect

269 to the criteria in the second level. Shown in Figure 2, the risk level assessment model consists of

270 three main levels. Level 0 is the risk level assessment problem. Level 1 consists of the twelve

271 qualitative factors. Level 2 represents the final output component risk level ranging from 0-100.

Figure 2 Hierarchy of the developed model which is a reciprocal matrix, were constructed as shown in Table 6. The matrix has a value of

278 " 1 " in the main diagonal, and elements below the main diagonal are reciprocal to the elements 279 above it $\left(a_{\mathrm{ji}}=1 / \mathrm{a}_{\mathrm{ij}}\right)$. The value of each $\mathrm{a}_{\mathrm{ij}}$ is calculated from the questionnaire responses. Dividing 280 the effect rank of variable $\mathrm{i}$ over the effect rank of variable $\mathrm{j}$ gives the matrix element $\mathrm{a}_{\mathrm{ij}}$. The 
281 number of elements in a matrix $n \times n$ elements are $n(n-1) / 2$ (Shappered and Cartwright 2000).

282 Therefore, the matrix can be expressed as follows:

283

$$
\left[\begin{array}{ccc}
1 & x & y \\
\frac{1}{x} & 1 & z \\
\frac{1}{y} & \frac{1}{z} & 1
\end{array}\right]
$$

Table 6: Risk level factors' pair-wise comparison matrix

\section{3- Assigning Priorities}

288 To attain the weight of each factor, the AHP methodology is applied to these factors.

289 Consequently, all pairwise comparison matrices, for main factors and subfactors, are filled with

290 numerical values, which represents the importance of each factor against the others.

\section{4- Establish Priority Vector}

293 In this step, the authors use Saaty's methodology to calculate the eigenvector or weighting vector

294 (Wi) for each pairwise matrix (Saaty 1999). The weight of each factor demonstrates this factor

295 among the other factors; however, the total value of these weights for each matrix is equal to 296 one.

\section{5- Consistency Analysis}

In this step, we verified if the consistency of a pair-wise comparison matrix that results in

300 the factors' weights can be considered. If the matrix is consistent, the weights are accepted.

\section{Page 14 of 36}


301 Otherwise, we have to return the weights to the experts to reassess their evaluation. The

302 consistency index (CI) and consistency ratio (CR) has been calculated as follows (Saaty 1999):

303

304

305

306

307

308

309

310

value is zero, which is less than 0.10 . Overall, the matrix is consistent and verified.

\section{6- Trenchless Technology Risk Level Assessment Model}

316 using Equation 7 on a scale from 0-100. The equation combines the different priority matrices

317 with the efficiency rating score which results in generating a risk level assessment value by a 318 summation of the results. According to this procedure, the risk level value can be calculated 319 using the following formula:

$$
Q F=\sum_{i=1}^{n} W_{i} * V_{i}
$$

Where:

$\mathrm{W}_{\mathrm{i}} \quad$ : Relative weight for variable number i 
$\mathrm{V}_{\mathrm{i}} \quad$ : Worth value for variable number $\mathrm{i}$

324

$\mathrm{n} \quad$ : Number of qualitative variables

325

326 Results

The previous steps were followed to analyze the responses of the questionnaire for the

329 qualitative factors. In the AHP model, the factors were ranked according to importance as shown

330 in Figure 3. We found that the most effective factor in risk level problems is acts of God

331 followed by water level change, M/T breakdown, pipeline leakage, injuries, and mislead of laser.

332 On the other hand, insufficient torque, ground settlement, schedule failure, soil condition change,

333 unforeseen conditions, and obstacles were the lowest ranked factors on the risk level factors in

334 the current study. The resulting weight after multiplying the eigenvector and the worth value of

335 each factor is shown in Table 7. This value can be interpreted as a multiplier to the risk

336 assessment prediction models of microtunneling projects to consider the combined effect of the

337 risk condition levels. prediction of microtunneling projects

\section{Validation of AHP model}


The validation process is to guarantee that the developed models best fit the available

347 data. To validate the AHP model, we divided the collected data into two data sets: $80 \%$ of data

348 for building the model, while $20 \%$ is for validation. We selected the validation data set $(20 \%)$

349 randomly and kept it as we developed the AHP model. Then we compared the predicted results

350 with the real values of the validation data set, as shown in Table 8. Equations 8 and 9 (Zayed and

351 Halpin 2005) were used to validate the developed AHP model as follows:

$352(\mathrm{AIP})=\sum_{\boldsymbol{i}=\mathbf{1}}^{\boldsymbol{n}}\{\mathbf{1}-\mathbf{I}(\mathbf{E i} / \mathbf{C i}) \mathbf{I}\} * 100 / \mathrm{n}$

$353(\mathrm{AVP})=100-\mathrm{AIP}$

354 Where AIP is the Average Invalidity Percent, AVP is the Average Validity Percent, $E_{i}$ is the $i^{\text {th }}$ 355 predicted value, $\mathrm{C}_{\mathrm{i}}$ is the $\mathrm{i}^{\text {th }}$ actual value, and $\mathrm{n}$ is the number of observations.

Table 8: Validation results of the developed model

359 The AVP and AIP values for productivity index model using AHP showed that:

$\mathrm{AIP}=10.41 \%$ and AVP $=89.59 \%$. These results indicated that the obtained results were satisfactory and acceptable, as shown in Figure 4.

363 Figure 4: AHP risk level assessment model validation shows actual cluster membership output versus predicted output percentage 


\section{Conclusion}

This research proposed an assessment model based on the risk level problems that affect

368 the installation of microtunneling projects. The model was developed by utilizing the cluster

369 analysis technique and AHP to assist the contractors in the bidding and operation phases of

370 microtunneling projects with higher efficiency and accuracy. This study proposed that the

371 qualitative factors of risk levels affecting the installation of microtunneling projects can be

372 evaluated using the AHP technique. Furthermore, the risk level assessment was calculated based

373 on the responses from a questionnaire administered to microtunneling-industry experts. The data

374 sets were then classified into homogenous groups using the cluster analysis technique. The SPSS

375 clustering technique was utilized to cluster the data through hierarchical clustering techniques

376 and the K-Means clustering analysis, which resulted in a 4 cluster membership output.

The AHP model resulted in ranking the factors from the highest to the lowest efficiency

379 on the risk level assessment, which shows that acts of God, water level change, M/T breakdown,

380 pipeline leakage, injuries, and mislead of laser are the highest effective factors, while insufficient

381 torque, ground settlement, schedule failure, soil condition change, unforeseen conditions, and

382 obstacles are the lowest ranked factors of the risk level factors.

383

384 Overall, the AHP model was validated with $89.59 \%$ Average Validity Percent (AVP), which is 385 considered a satisfactory result. Consequently, the PI model is valid and accepted for practice use 386 in the real world.

\section{Page 18 of 36}




\section{Page 19 of 36}

https://mc06.manuscriptcentral.com/cjce-pubs 


\section{References}

389

390

391

392

393

394

395

396

397

398

399

400

401

402

403

404

405

406

407

408

409

410

Ali, S., Zayed, T., \& Hegab, M. 2007. Modeling the effect of subjective factors on productivity of trenchless technology application to buried infrastructure systems. Journal of Construction Engineering and Management, 133(10), 743-748.

Ariaratnam, S. T., Harbin, B. C., \& Stauber, R. L. 2007. Modeling of annular fluid pressures in horizontal boring. Tunnelling and Underground Space Technology, 22(5-6), 610-619. https://doi.org/10.1016/j.tust.2007.01.001

Coakes, S. J., \& Steed, L. 2009. SPSS: Analysis Without Anguish Using Spss Version 14.0 for Windows. New York, NY, USA: John Wiley \& Sons, Inc.

Elwakil, E. 2011. Knowledge discovery based simulation system in construction. Concordia University. Retrieved from http://spectrum.library.concordia.ca/7688/

Gierczak, M. 2014. The qualitative risk assessment of MINI, MIDI and MAXI horizontal directional drilling projects. Tunnelling and Underground Space Technology, 44, 148156. https://doi.org/10.1016/j.tust.2014.07.010

Hashemi, S. B. 2008. Construction Cost of Underground Infrastructure Renewal: A Comparison of Traditional Open-cut and Pipe Bursting Technology. ProQuest.

Hegab, M. Y., \& Salem, O. M. 2010. Ranking of the factors affecting productivity of microtunneling projects. Journal of Pipeline Systems Engineering and Practice, 1(1), 4252.

Hyun, K.-C., Min, S., Choi, H., Park, J., \& Lee, I.-M. 2015. Risk analysis using fault-tree analysis (FTA) and analytic hierarchy process (AHP) applicable to shield TBM tunnels. Tunnelling and Underground Space Technology, 49, 121-129. https://doi.org/10.1016/j.tust.2015.04.007

\section{Page 20 of 36}


411 IBM Knowledge Center - Hierarchical Cluster Analysis. 2013, January 1. [CT701]. Retrieved 412 July 6,2015 , from http://www01.ibm.com/support/knowledgecenter/SSLVMB_20.0.0/com.ibm.spss.statistics.help/idh_

Jain, A. K., Murty, M. N., \& Flynn, P. J. 1999. Data Clustering: A Review. ACM Comput. Surv., 31(3), 264-323. https://doi.org/10.1145/331499.331504

Khondoker, M. T. H., Yi, Y., \& Bayat, A. 2016. Comparison of different methods for normal stress calculation during pipe jacking/microtunneling. International Journal of Geotechnical Engineering, 1-11.

Ma, B., Najafi, M., Shen, H., \& Wu, L. 2010. Risk Evaluation for Maxi Horizontal Directional Drilling Crossing Projects. Journal of Pipeline Systems Engineering and Practice, 1(2). https://doi.org/10.1061/(ASCE) PS.1949-1204.0000046

Moganti, P. 2016. Safety Risk Investigation of Horizontal Directional Drilling Projects. All Theses. Retrieved from http://tigerprints.clemson.edu/all_theses/2451

Marzouk, M., Abdallah M., \& El-Said, M. 2010. Modeling Microtunneling Projects using Computer Simulation. Journal of Construction Engineering and Management, 136(6), 670-682. https://doi.org/10.1061/(ASCE)CO.1943-7862.0000169

431 Mohanapriya, S., \& Kumar, S. 2015. Application of Trenchless Technology In Urban Infrastructure. In International Journal of Innovative Research in Engineering \& Management (IJIREM) (Vol. 3). Coimbatore, India: Department of CIVIL Engineering,

\section{Page 21 of 36}


434

435

436

437

438

439

440

441

442

443

444 Chung, T. H., Abraham, D. M., \& Gokhale S.B. 2004. Decision Support System for

445

446

447

448

449

450

451

452

453

454

455

456

Sri Ramakrishna Institute of Technology. Retrieved from https://www.researchgate.net/profile/Sindhu_Vaardini/publication/282003570_Applicatio n_of_Trenchless_Technology_In_Urban_Infrastructure/links/560111db08aeafc8ac8c7f $7 b$ .$p d f$

Saaty, T. L. 1999. Decision making for leaders: the analytic hierarchy process for decisions in a complex world (Vol. 2). RWS publications. Retrieved from https://books.google.com/books?hl=en\&lr=\&id=c8KqSWPFwIUC\&oi=fnd\&pg=PT8\&d $\mathrm{q}=$ Decision+Making + for + Leaders: + The + Analytic + Hierarchy + Process + for + Decision + in $+\mathrm{a}+$ Complex + World $\%$ E2\%80\%9D.\&ots=2KNSGoFSMk\&sig=7GvMCvsIA9cz_Ay0hyz OfgeR0t4 Microtunneling Applications. Journal of Construction Engineering and Management, 130(6), 835-843. https://doi.org/10.1061/(ASCE)0733-9364(2004)130:6(835)

Zayed, T., \& Mahmoud, M. 2013. Data acquisition and factors impacting productivity of Horizontal Directional Drilling (HDD). Tunnelling and Underground Space Technology, $33,63-72$.

Zayed, T., \& Mahmoud, M. 2013. Data acquisition and factors impacting productivity of Horizontal Directional Drilling (HDD). Tunnelling and Underground Space Technology, 33, 6372.

Zayed, T., \& Mahmoud, M. 2014. Neurofuzzy-based productivity prediction model for horizontal directional drilling. Journal of Pipeline Systems Engineering and Practice, 5(3), 04014004.

Page 22 of 36

https://mc06.manuscriptcentral.com/cjce-pubs 


\section{Tables}

Table 1: Risk level problems factors from questionnaire

\begin{tabular}{|c|c|c|}
\hline Factor & \# & Explanation \\
\hline (1) & (2) & (3) \\
\hline Obstacles & 1 & A thing that blocks one's way or prevents progress \\
\hline & 2 & The condition of soil is changed quickly based on \\
\hline Change & & environmental factors such as changes in moisture. \\
\hline Unforeseen & & Unexpected circumstance or situation that affects the \\
\hline Condition & & final price and/or completion time of a project. \\
\hline Mislead of Laser & 4 & Miss alignment due to the need of calibration \\
\hline M/T Breakdown & 5 & Using the appropriate machine (slurry or EPB) \\
\hline Water Level & & Groundwater level change due to natural phenomena \\
\hline Change & & and others are caused by man's activities. \\
\hline & 7 & Insufficient twisting force \\
\hline Torque & & \\
\hline Acts of God & 8 & $\begin{array}{l}\text { An instance of uncontrollable natural forces in } \\
\text { operation }\end{array}$ \\
\hline Pipeline Leakage & 9 & $\begin{array}{l}\text { Pipeline leak detection is used to determine if and in } \\
\text { some cases where a leak has occurred in systems } \\
\text { which contain liquids and gases. }\end{array}$ \\
\hline Injuries & 10 & An instance of being injured \\
\hline
\end{tabular}




\begin{tabular}{lll}
\hline Schedule Failure & An excessively aggressive schedule results in \\
& 11 mistakes being made from which the project never \\
& recovers. \\
\hline Ground Settlement & Differential or uneven settlement occurs when the \\
12 & soil beneath a structure cannot bear the weights \\
& imposed.
\end{tabular}


Variables Original scale Fuzzy scale Worth Value $\left(\mathrm{V}_{\mathrm{I}}\right)$

(1)

\begin{tabular}{|c|c|c|c|}
\hline Obstacles & 2.1 & 4.2 & 0.42 \\
\hline Soil Condition Change & 2.6 & 5.2 & 0.52 \\
\hline Unforeseen Condition & 2.2 & 4.4 & 0.44 \\
\hline Mislead of Laser & 3.25 & 6.5 & 0.65 \\
\hline M/T Breakdown & 2.45 & 6.9 & 0.69 \\
\hline Water Level Change & 3.65 & 7.3 & 0.73 \\
\hline Insufficient Torque & 3.2 & 6.4 & 0.64 \\
\hline Acts of God & 3.7 & 7.4 & 0.74 \\
\hline Pipeline Leakage & 3.45 & 6.9 & 0.69 \\
\hline Injuries & 3.4 & 6.8 & 0.68 \\
\hline Schedule Failure & 3 & 6 & 0.6 \\
\hline Ground Settlement & 3.2 & 6.4 & 0.64 \\
\hline
\end{tabular}




\begin{tabular}{|c|c|c|c|c|c|c|}
\hline \multicolumn{7}{|c|}{ Agglomeration Schedule } \\
\hline Stage & Cluster & & Coefficients & Stage & & Next \\
\hline & Cluster 1 & Cluster & & Cluster 1 & Cluster 2 & \\
\hline 1 & 24 & 25 & 0 & 0 & 0 & 2 \\
\hline 2 & 5 & 24 & 0 & 0 & 1 & 5 \\
\hline 3 & 21 & 22 & 1.5 & 0 & 0 & 18 \\
\hline 4 & 16 & 20 & 5.542 & 0 & 0 & 6 \\
\hline 5 & 4 & 5 & 10.042 & 0 & 2 & 10 \\
\hline 6 & 16 & 18 & 15.995 & 4 & 0 & 9 \\
\hline 7 & 1 & 6 & 22.495 & 0 & 0 & 16 \\
\hline 8 & 10 & 11 & 29.495 & 0 & 0 & 19 \\
\hline 9 & 14 & 16 & 36.857 & 0 & 6 & 12 \\
\hline 10 & 4 & 15 & 44.757 & 5 & 0 & 11 \\
\hline 11 & 4 & 8 & 52.691 & 10 & 0 & 15 \\
\hline 12 & 13 & 14 & 62.536 & 0 & 9 & 17 \\
\hline 13 & 17 & 23 & 73.536 & 0 & 0 & 19 \\
\hline 14 & 3 & 7 & 84.536 & 0 & 0 & 20 \\
\hline 15 & 4 & 12 & 96.488 & 11 & 0 & 20 \\
\hline 16 & 1 & 19 & 108.655 & 7 & 0 & 22 \\
\hline 17 & 9 & 13 & 122.308 & 0 & 12 & 18 \\
\hline 18 & 9 & 21 & 138.27 & 17 & 3 & 22 \\
\hline 19 & 10 & 17 & 154.77 & 8 & 13 & 21 \\
\hline 20 & 3 & 4 & 176.818 & 14 & 15 & 21 \\
\hline 21 & 3 & 10 & 214.83 & 20 & 19 & 23 \\
\hline 22 & 1 & 9 & 254.12 & 16 & 18 & 23 \\
\hline 23 & 1 & 3 & 354.126 & 22 & 21 & 0 \\
\hline
\end{tabular}




\section{RISK LEVEL OF PROBLEMS}

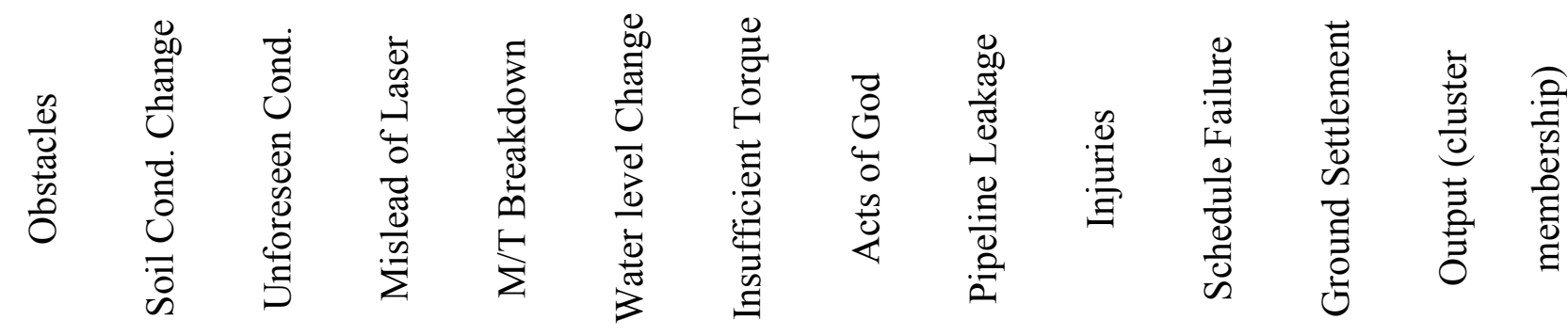

\begin{tabular}{|c|c|c|c|c|c|c|c|c|c|c|c|c|}
\hline 4 & 4 & 4 & 3 & 3 & 1 & 3 & 3 & 3 & 1 & 2 & 2 & 1 \\
\hline 1 & 1 & 1 & 3 & 3 & 5 & 4 & 4 & 4 & 4 & & 4 & 4 \\
\hline 2 & 1 & 2 & 3 & 5 & 4 & 5 & 3 & 4 & 2 & 3 & 5 & 4 \\
\hline 1 & 2 & 1 & 5 & 4 & 5 & 4 & 5 & 4 & 5 & 3 & 3 & 4 \\
\hline 1 & 3 & 2 & 4 & 4 & 5 & 3 & 4 & 4 & 5 & 4 & 3 & 4 \\
\hline 3 & 3 & 5 & 3 & 4 & 2 & 3 & 1 & 1 & 1 & 2 & 2 & 1 \\
\hline 2 & 2 & 1 & 4 & 4 & 4 & 3 & 1 & 4 & 5 & 4 & 5 & 4 \\
\hline 2 & 3 & 2 & 5 & 4 & 4 & 3 & 5 & 5 & 5 & 5 & 5 & 4 \\
\hline 3 & 4 & 3 & 1 & 1 & 3 & 1 & 5 & 4 & 3 & 3 & 3 & 2 \\
\hline 5 & 3 & 4 & 4 & 5 & 4 & 5 & 4 & 4 & 4 & 4 & 3 & 3 \\
\hline 3 & 2 & 2 & 3 & 5 & 5 & 4 & 5 & 4 & 4 & 4 & 2 & 3 \\
\hline 1 & 1 & 1 & 3 & 3 & 3 & 3 & 5 & 3 & 5 & 4 & 3 & 4 \\
\hline 1 & 1 & 1 & 1 & 1 & 3 & 3 & 3 & 3 & 3 & 1 & 3 & 2 \\
\hline 1 & 2 & 2 & 1 & 3 & 5 & 2 & 3 & 4 & 3 & 3 & 2 & 2 \\
\hline 2 & 4 & 3 & 5 & 5 & 5 & 4 & 4 & 3 & 4 & 3 & 4 & 3 \\
\hline 2 & 3 & 2 & 3 & 4 & 4 & 3 & 4 & 4 & 4 & 3 & 3 & 4 \\
\hline 4 & 4 & 2 & 5 & 4 & 2 & 3 & 4 & 3 & 3 & 3 & 4 & 1 \\
\hline 1 & 3 & 1 & 3 & 2 & 4 & 2 & 4 & 3 & 3 & 2 & 4 & 2 \\
\hline 1 & 3 & 2 & 4 & 3 & 2 & 3 & 4 & 2 & 1 & 2 & 2 & 1 \\
\hline 2 & 3 & 3 & 2 & 2 & 3 & 3 & 3 & 3 & 3 & 2 & 2 & 2 \\
\hline
\end{tabular}




\begin{tabular}{lllllllllllll}
\hline 3 & 2 & 2 & 3 & 3 & 3 & 2 & 2 & 4 & 3 & 2 & 1 & 2 \\
\hline 3 & 2 & 1 & 3 & 3 & 3 & 1 & 3 & 4 & 3 & 2 & 1 & 2 \\
\hline 5 & 5 & 5 & 3 & 4 & 4 & 3 & 5 & 3 & 3 & 4 & 5 & 3 \\
\hline 1 & 3 & 2 & 4 & 4 & 5 & 3 & 4 & 4 & 5 & 4 & 3 & 4 \\
\hline 1 & 3 & 2 & 4 & 4 & 5 & 3 & 4 & 4 & 5 & 4 & 3 & 4
\end{tabular}

468

469

\section{Page 28 of 36}

https://mc06.manuscriptcentral.com/cjce-pubs 
Table 5: Classifying the clusters into six clusters based on a fuzzy scale

\begin{tabular}{ccc}
\hline Cluster Membership & Fuzzy Scale & Assessment Condition \\
\hline 1 & 100 & Very low \\
2 & 83.3 & Low \\
3 & 66.67 & Medium \\
4 & 50.00 & High \\
\hline
\end{tabular}

471

472 


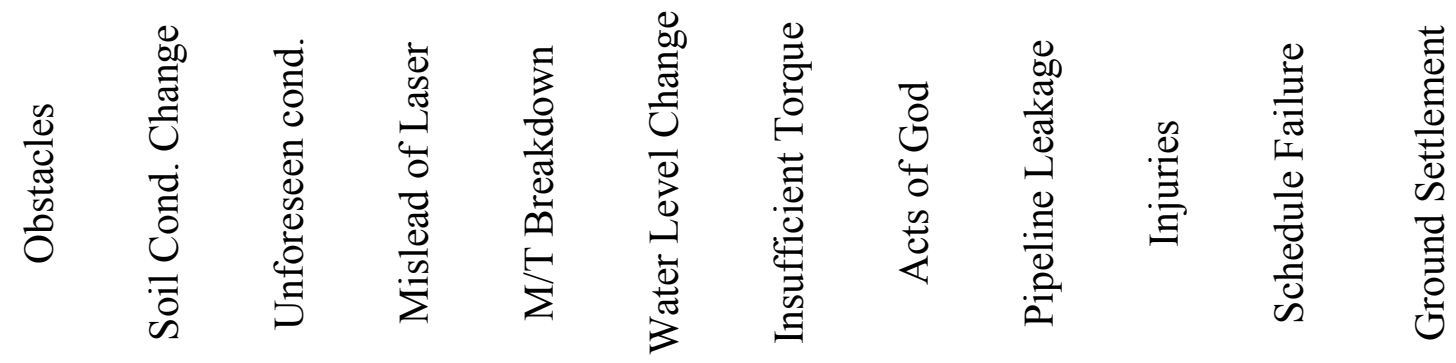

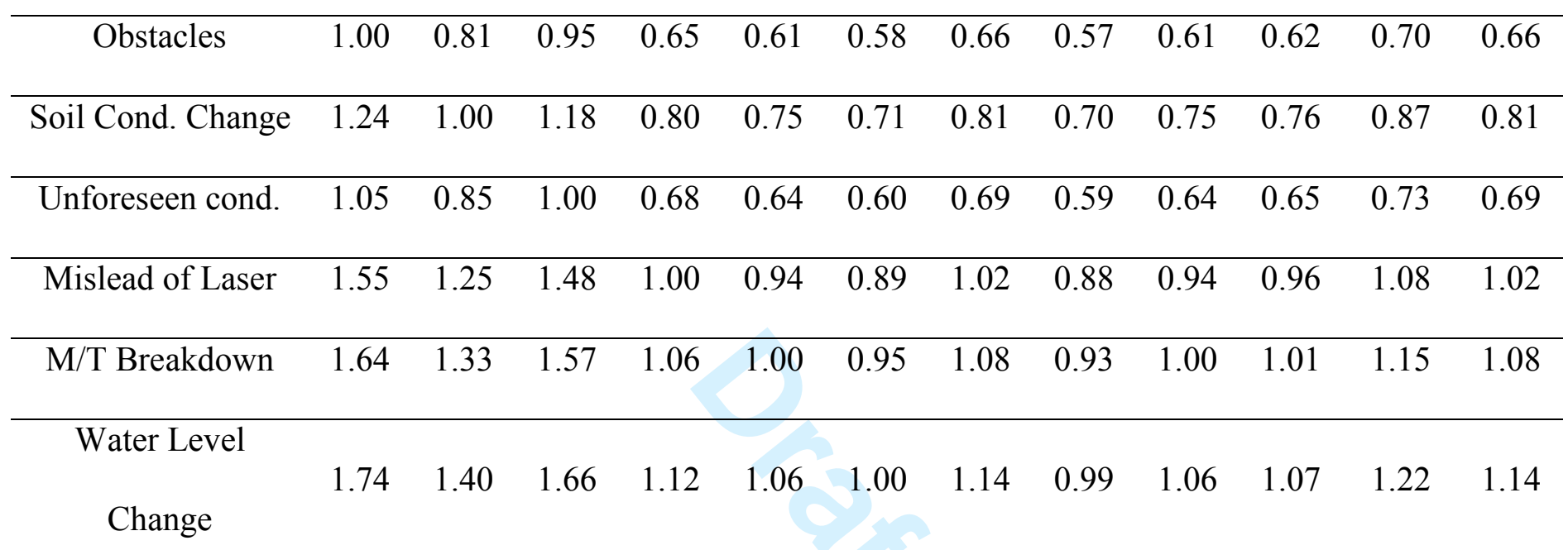

Insufficient

Torque

$\begin{array}{llllllllllll}1.52 & 1.23 & 1.45 & 0.98 & 0.93 & 0.88 & 1.00 & 0.86 & 0.93 & 0.94 & 1.07 & 1.00\end{array}$

$\begin{array}{lllllllllllll}\text { Acts of God } & 1.76 & 1.42 & 1.68 & 1.14 & 1.07 & 1.01 & 1.16 & 1.00 & 1.07 & 1.09 & 1.23 & 1.16\end{array}$

$\begin{array}{lllllllllllll}\text { Pipeline Leakage } & 1.64 & 1.33 & 1.57 & 1.06 & 1.00 & 0.95 & 1.08 & 0.93 & 1.00 & 1.01 & 1.15 & 1.08\end{array}$ $\begin{array}{lllllllllllll}\text { Injuries } & 1.62 & 1.31 & 1.55 & 1.05 & 0.99 & 0.93 & 1.06 & 0.92 & 0.99 & 1.00 & 1.13 & 1.06\end{array}$

$\begin{array}{lllllllllllll}\text { Schedule Failure } & 1.43 & 1.15 & 1.36 & 0.92 & 0.87 & 0.82 & 0.94 & 0.81 & 0.87 & 0.88 & 1.00 & 0.94\end{array}$

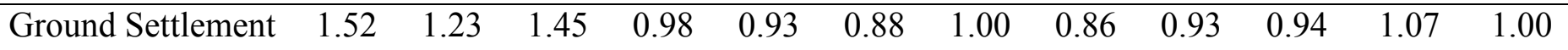
474

475 
477

\begin{tabular}{|c|c|c|c|}
\hline Factors & Eigenvector & Worth Value (Vi) & $\mathrm{W}^{*} \mathrm{Vi}$ \\
\hline Acts of God & 0.099 & 0.74 & 0.074 \\
\hline Water Level Change & 0.098 & 0.73 & 0.072 \\
\hline M/T Breakdown & 0.093 & 0.69 & 0.064 \\
\hline Pipeline Leakage & 0.093 & 0.69 & 0.064 \\
\hline Injuries & 0.091 & 0.68 & 0.062 \\
\hline Mislead of laser & 0.087 & 0.65 & 0.057 \\
\hline Insufficient Torque & 0.086 & 0.64 & 0.055 \\
\hline Ground Settlement & 0.086 & 0.64 & 0.055 \\
\hline Schedule Failure & 0.081 & 0.6 & 0.048 \\
\hline Soil Condition Change & 0.070 & 0.52 & 0.036 \\
\hline Unforeseen conditions & 0.059 & 0.44 & 0.026 \\
\hline Obstacles & 0.056 & 0.42 & 0.024 \\
\hline
\end{tabular}



Table 8: Validation results of the developed model

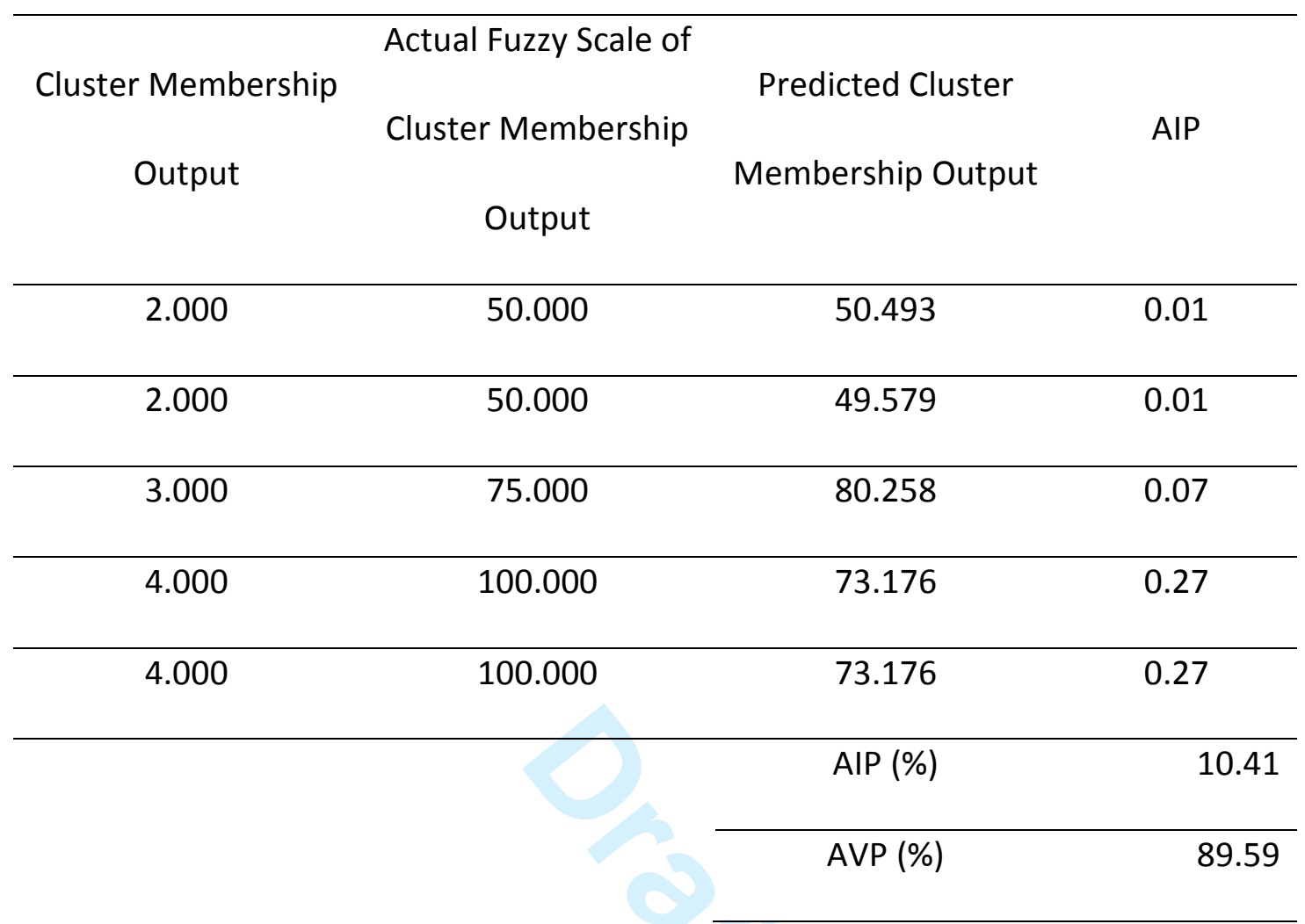




\section{List of Figure Captions}

484

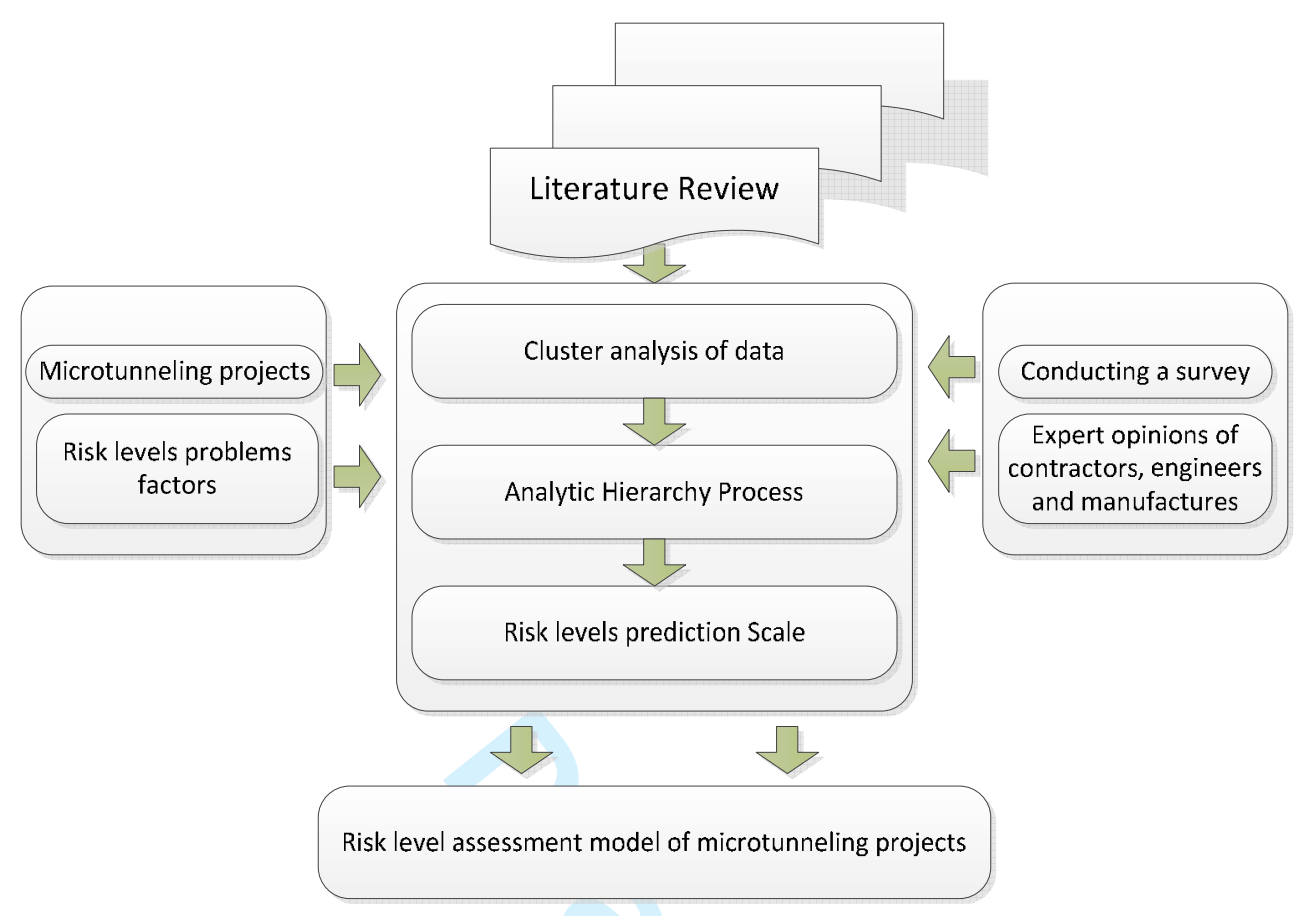

486

487

Figure 1. Research Methodology

488

\section{Page 33 of $\mathbf{3 6}$}

https://mc06.manuscriptcentral.com/cjce-pubs 


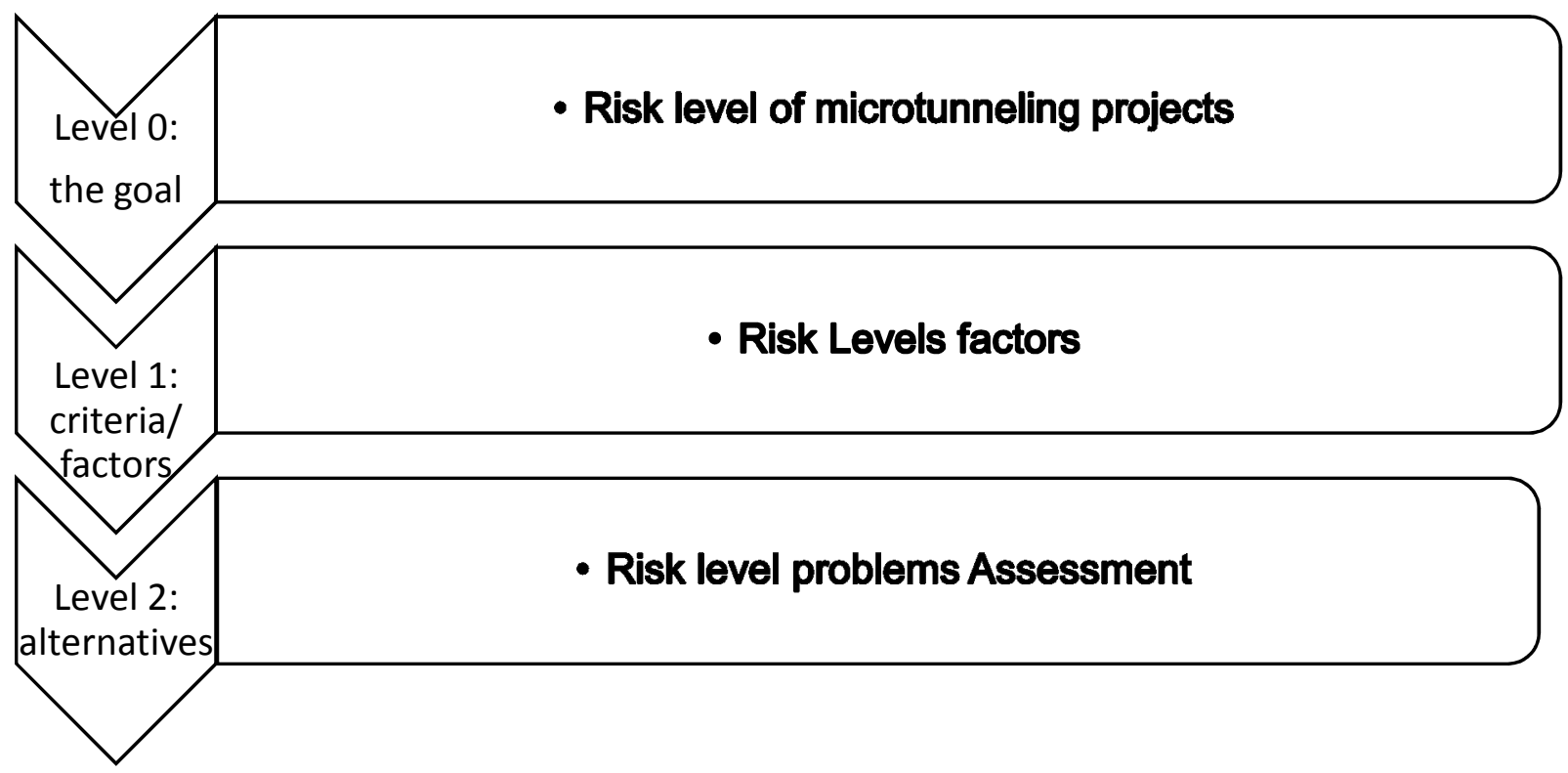

Figure 2. Hierarchy of the developed model 


\section{Factors weight}

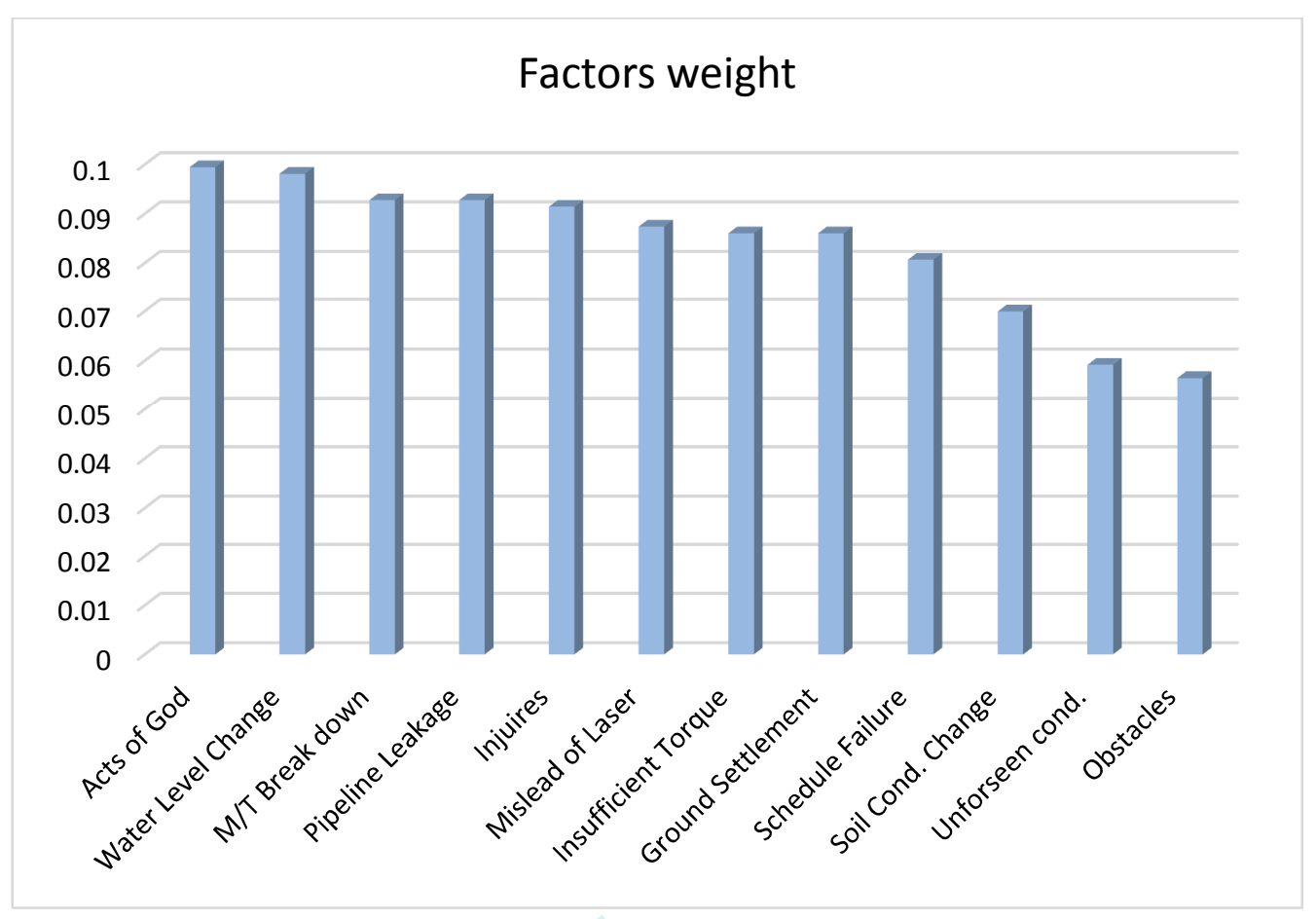

493 Figure 3. Total combination weights of qualitative factors' effect on the risk level problems 


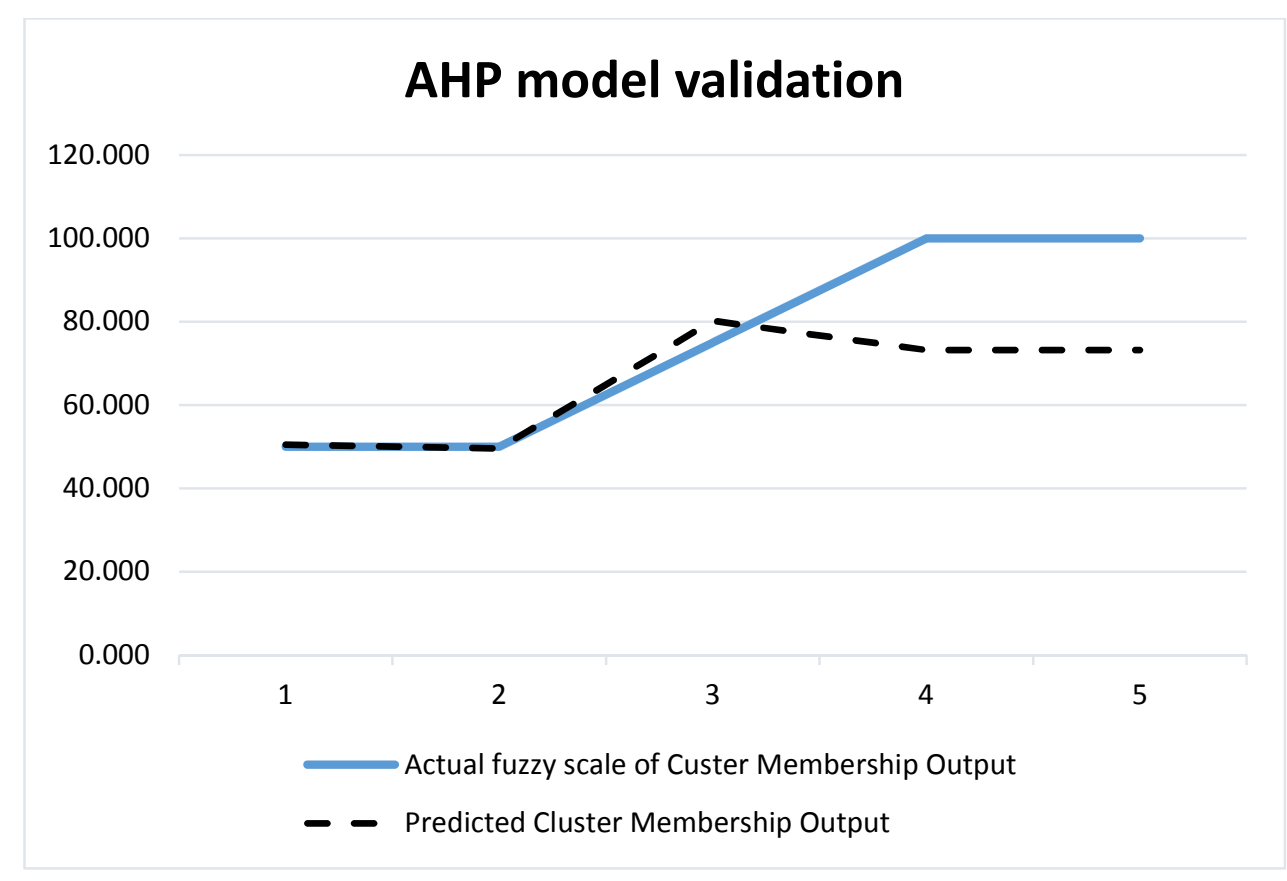

497 Figure 4. AHP risk level assessment model validation shows actual cluster membership output 